\title{
Repeated Cold Atmospheric Plasma Application to Intact Skin Does Not Cause Sensitization in a Standardized Murine Model
}

\author{
Julia van der Linde, ${ }^{\mathrm{a},{ }^{*}}$ Kim Rouven Liedtke, ${ }^{a}$ Rutger Matthes, ${ }^{\mathrm{b}}$ Axel Kramer, ${ }^{\mathrm{c}}$ \\ Claus-Dieter Heidecke, ${ }^{a}$ \& Lars Ivo Partecke ${ }^{a}$ \\ aDepartment of General, Visceral, Thoracic, and Vascular Surgery, University Medicine Greifswald, \\ 17475 Greifswald, Germany; 'Unit of Periodontology, Dental School, University Medicine \\ Greifswald, 17475 Greifswald, Germany; Institute of Hygiene and Environmental Medicine, \\ University Medicine Greifswald, 17475 Greifswald, Germany \\ *Address all correspondence to: Julia van der Linde, MD, Surgical Research Laboratory, Department of General, Visceral, \\ Thoracic, and Vascular Surgery, University Medicine Greifswald, Diagnostic Center, 17475 Greifswald, Germany; Tel.: \\ +493834 865590; Fax: +493834 865591, E-mail: Julia.vanderLinde@uni-greifswald.de
}

\begin{abstract}
Cold atmospheric plasma (CAP) is a promising option for the treatment of chronic wounds and superficial cancer. Recent studies show that CAP has excellent microbicidal and antibiofilm activity, stimulates angiogenesis and cell proliferation, and induces apoptosis in cancer cells. The kINPen MED transportable plasma jet is a certified medical device that needs to be tested for irritant and allergenic side effects. We used a murine local lymph node assay (according to the Organisation for Economic Co-operation and Development protocol) to evaluate the kINPen MED's potential to trigger skin sensitization. Our results showed that $25 \mathrm{~s}$ of CAP exposure did not induce skin sensitization compared with the vehicle control (acetone/olive oil mixture). The CAP-treated group had a stimulation index (SI) of 0.76, which was significantly lower than the $>1.8$ threshold $(\mathrm{SI}=0.46$ for the vehicle control group). Pure argon gas flow also did not induce sensitization. Moreover, we did not observe any serious effects on proliferation activity in local lymph nodes (assessed via visual analysis, adenosine triphosphate content, and histology). This study confirmed that the use of the kINPen MED device did not cause any harmful sensitization or irritation in a murine model.
\end{abstract}

KEY WORDS: tissue-tolerable plasma, nonthermal plasma, skin sensitization, local lymph node assay, irritant contact dermatitis, risk assessment

\section{INTRODUCTION}

Although physical plasma is commonly referred to as a nonclassical state of matter, describing an ionized, high-energy proportionate in a gas, the development of tissuetolerable cold atmospheric plasma (CAP) has opened a wide range of possible biological and medical applications. ${ }^{1}$ These applications of CAP demonstrate excellent microbicidal and antibiofilm activity, ${ }^{2,3}$ positive effects for angiogenesis, ${ }^{4,5}$ and the ability to induce apoptosis but not necrosis in cancer cells. ${ }^{6-8}$ Plasma medicine is a fast-developing area of medical research. ${ }^{9}$ Thus, there is particular interest in the effects of CAP on sterilization, ${ }^{10,11}$ wound healing, dental therapy, ${ }^{12}$ dermatology, ${ }^{13}$ and anticancer treat- 
ment. ${ }^{8}$ Although the interaction between CAP and living tissue is not yet fully understood, a comprehensive medical CAP application may be possible in the future. Several animal and human studies have generated promising results on both the effectiveness and safety of CAP. Consequently, in 2013, the European Commission approved and granted CE markings (class IIb medical device) for two plasma sources: kINPen MED (Neoplas Tools GmbH, Greifswald, Germany) and PlasmaDerm (Cynogy, Duderstadt, Germany). ${ }^{14}$

Because the irritative and sensitizing potency of CAP (particularly kINPen MED transportable plasma) has not yet been tested and is a prerequisite for CAP application on the skin, wounds, and mucous membranes, this study analyzes this potency for the first time. The Interagency Coordinating Committee on the Validation of Alternative Methods (ICCVAM) and the Organisation for Economic Co-operation and Development (OECD) have approved experimental protocols such as the local lymph node assay (LLNA), modified by Daicel (LLNA:DA, no. 442a, 10 June 2010), which is highly suitable for detecting dose-dependent skin sensitization. ${ }^{15,16}$ In this setting, lymphocyte proliferation in local lymph nodes is measured by the amount of adenosine triphosphate (ATP), which correlates highly with the total cell number. ${ }^{17}$

In contrast with allergic contact dermatitis, irritant contact dermatitis is caused by physical or chemical irritation with an immediate reaction, leading to skin inflammation with direct damage to keratinocytes and neutrophil infiltration. ${ }^{17,18}$

The plasma jet generates a well-characterized CAP that does not seem to be dangerous from either a physical (temperature, ultraviolet [UV] radiation, ozone) or biological point of view (cytotoxicity, depth of penetration, mutagenicity). ${ }^{19,20}$ Although existing studies have not yet demonstrated sensitization after the application of CAP to intact skin, ${ }^{21}$ there are currently no in vivo studies that uncover the possible sensitization potential of CAP by exploring the local lymph node reaction. CAP is not a conventional topical medicament, it generates potential hazardous effectors, such as different radical species (nitric oxide, nitrogen dioxide) and reactive oxygen species (ozone, superoxide, and hydroxyl radicals), as well as UV radiation and a flux of charges. Reactive oxygen and nitrogen species play a key role in both inducing sensitization ${ }^{22}$ and mediating the effects of CAP. ${ }^{23,24}$ We investigated the sensitization potential of repeated CAP application, generated by an atmospheric pressure argon plasma jet (kINPen MED), in vivo on the basis of the LLNA:DA assay.

\section{MATERIALSAND METHODS}

\section{A. CAP Generation}

CAP was generated by the kINPen MED atmospheric pressure argon plasma jet (Neoplas Tools), which is accredited as a medical device. The hand-held unit contains a mounted rod-like electrode that is shielded by a dielectric capillary. Using $4 \mathrm{~L} / \mathrm{min}$ of argon flow (99.999\%, Ar 5.0; ALPHAGAZ, Dusseldorf, Germany), CAP was ignited by generating a sinusoidal voltage with a frequency of about $1 \mathrm{MHz}$. 


\section{B. CAP Treatment Regimen In Vivo}

Following the LLNA guidelines, this experiment was carried out using female 9-weekold CBA/J mice (Charles River Laboratories, Sulzfeld, Germany) with access to food and water ad libitum. ${ }^{25}$ The animals were randomly divided into four treatment regimens (Fig. 1A; Table 1), in which they received either a liquid positive control [ $25 \%$ hexyl cinnamic aldehyde in acetone/olive oil $(4: 1, \mathrm{v} / \mathrm{v})$ ] or a liquid negative control [acetone/ olive oil $(4: 1, \mathrm{v} / \mathrm{v})]$, and gaseous CAP or pure argon gas flow as an additional vehicle control was applied to the dorsum of each ear. While the first two groups were challenged with $10 \mu \mathrm{L}$ of liquid per ear, the second two groups were exposed to gaseous matter for $25 \mathrm{~s}$ with a capillary tip to skin distance of $5 \mathrm{~mm}$. The treatment was performed on days 1, 2, 3, and 7 (Fig. 1B). One hour prior to treatment, mice were anesthetized with 4\% isoflurane (CP-Pharma, Burgdorf, Germany) and both ears were thoroughly cleaned using $1 \%$ sodium dodecyl sulfate. On day 8 , mice were euthanized and retroauricular lymph nodes were sampled (Fig. 1C). The local ethics committee approved the mouse experiments (application number 7221.3.-1.-010/13). Animal health and weight was monitored daily.

\section{ATP Determination}

Lymph nodes from both sides were washed in phosphate-buffered saline (PBS) (Gibco, Grand Island, NY, USA) and weighed. The tissue samples were then mashed, homogenized in $1 \mathrm{~mL}$ PBS, and diluted 1:10 in PBS again. Then $100 \mu \mathrm{L}$ was mixed with bioluminescent CellTiter-Glo substrate (Promega, Madison, WI, USA) in a 96-well plate (Eppendorf, Hamburg, Germany), shaken, and incubated at room temperature for 10 min, which was followed by optical read-out at $\lambda=562 \mathrm{~nm}$ using a Tecan M200 Pro (Tecan, Männedorf, Switzerland). The determined relative luminescence (RLU) is linearly dependent on ATP content. Thus, a standard curve was prepared for calculating ATP concentration. Due to the postmortem instability of ATP, care was taken not to exceed a period of $20 \mathrm{~min}$ from euthanasia to substrate addition. ${ }^{26}$

\section{Tissue Sections and Immunofluorescence}

After the animals were euthanized and the lymph nodes were prepared, a piece of each ear was retrieved using a punch (4-mm diameter; PFM Medical AG, Köln, Germany) and was then embedded in TissueTek (Sakura Finetek, Alphen aan den Rijn, The Netherlands) and stored in liquid nitrogen. Thin sections of the ears were cut and incubated with hematoxylin and eosin (Sigma, St. Louis, MO, USA), and samples were then mounted on microscopy slides using Faramount mounting medium (Agilent, Waldbronn, Germany). Tissue sections were investigated microscopically using a Keyence BZ-9000 microscope and were evaluated with BZ-II-Analyzer 4.6.2.2 (Keyence, Osaka, Japan).

Volume 7, Issue 4, 2017 

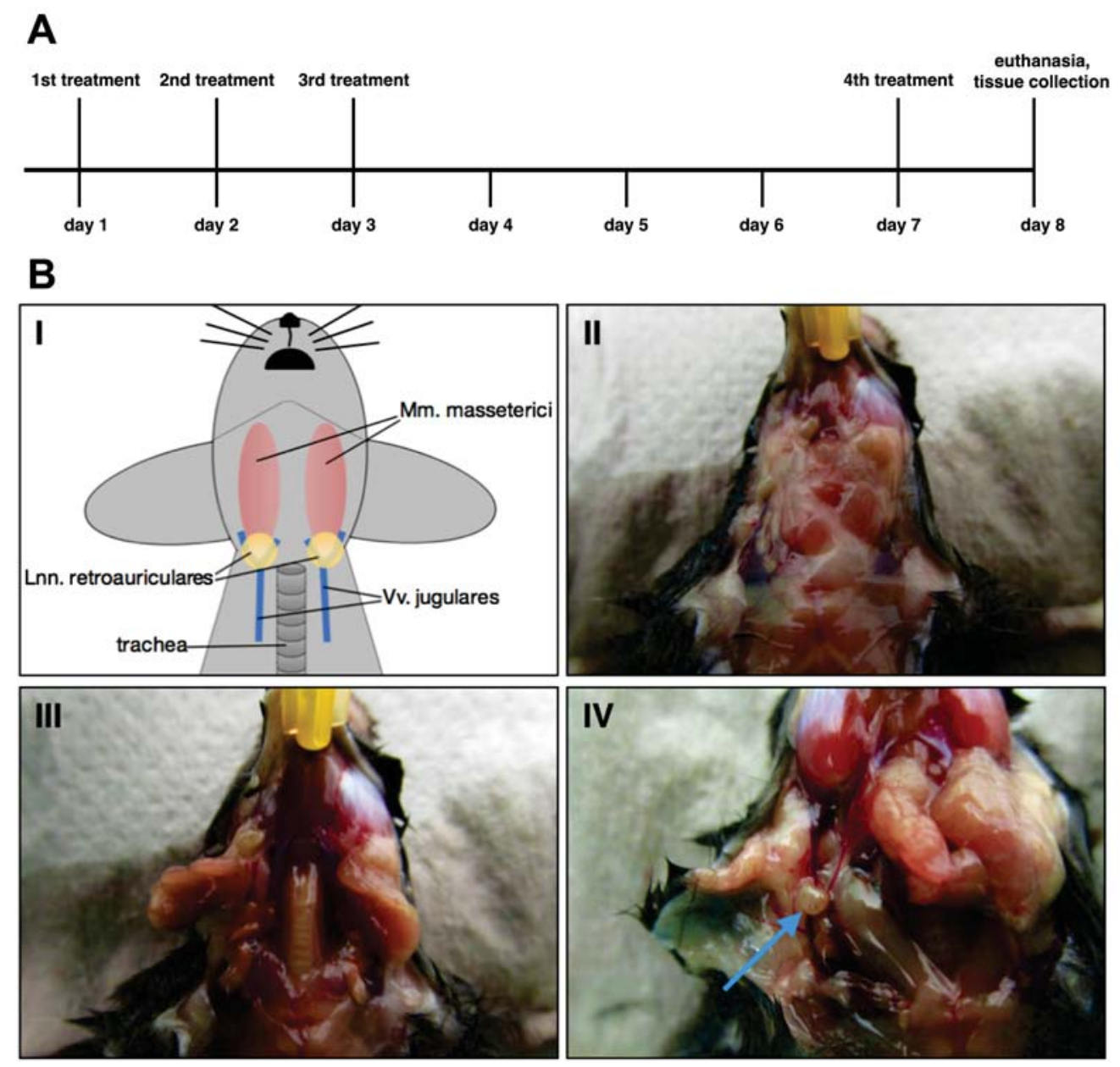

FIG. 1: Treatment procedure and lymph node preparation. (A) Treatment was carried out on days $1,2,3$, and 7, followed by euthanasia and tissue collection on day 8. (B) Schematic anatomy of the cervical region, showing the retroauricular lymph nodes (Lnn.), the masseteric muscles ( $\mathrm{Mm}$.), jugular veins ( $\mathrm{Vv}$.) and the trachea. As example, a male C57Bl/6 CCR4 ${ }^{-/}$mouse was used. Yellow structure (II, III): fixation needle. Lnn, nodi lymphatici; Mm, musculi; Vv, venae.

\section{E. Statistical Analysis}

Statistical analysis was carried out using GraphPad Prism software (version 6.07; GraphPad Software Inc., La Jolla, CA, USA). The nonparametric Kruskal-Wallis test was applied to compare lymph node weight, RLU values, and ATP concentrations. The calculated mean RLU values of each test group were used to detect statistical differences between the test groups and to calculate the dimensionless stimulation index (SI). Therefore, the mean RLUs of all four groups were divided by the mean of the liquid negative 
TABLE 1: Experimental setting

\begin{tabular}{|l|l|l|l|l|}
\hline $\begin{array}{l}\text { Treatment } \\
\text { Regimen }\end{array}$ & Positive Control & Vehicle Control & CAP & Ar Gas Flow \\
\hline Application & $\begin{array}{l}\text { 25\% hexyl cinnamic } \\
\text { aldehyde in acetone/ } \\
\text { olive oil (4:1) }\end{array}$ & $\begin{array}{l}\text { Acetone/olive oil } \\
(4: 1)\end{array}$ & $\begin{array}{l}\text { 25 s of CAP } \\
\text { treatment } \\
\text { with the kIN- } \\
\text { Pen MED }\end{array}$ & $\begin{array}{l}\text { 25 s of Ar gas } \\
\text { flow }\end{array}$ \\
\hline
\end{tabular}

Ar, argon; CAP, cold atmospheric plasma.

control; consequently, the liquid negative control SI $=1$. Following ICCVAM guidance, substances causing an SI $>1.8$ were determined to be potential skin sensitizers. 25 All data are presented as means \pm SEM. The significance level was indicated as $\alpha=0.05$.

\section{RESULTS}

\section{A. Repeated CAPTreatmentDid NotProvoke PersistentLocal Skin Reaction}

Instantaneous to the application of each substance, mice developed local short-lasting hyperemia, but this hyperemia advanced to a slight local erythema only in the positive control group. Besides this finding, there was no indication of increased illness in any of the animals.

In support of this, no abnormality in histological skin architecture was detected after exposure to CAP or one of the negative controls, whereas the positive control substance led to a higher cell number, cell swelling, and locally disrupted stratum corneum (Fig. 2).

\section{B. Charac teristics of Skin Sensitization Were Not Present In Vivo after CAP Treatment}

In cases of inflammatory skin reaction, lymphocytes proliferate in local lymph nodes, resulting in larger and heavier structures. Therefore, retroauricular lymph nodes were weighed prior to processing. The mean weight was $4.3 \pm 0.7 \mathrm{mg}$ for the positive control and $3.2 \pm 0.3 \mathrm{mg}$ for the liquid negative control. Both CAP treatment and argon led to even lower weights of $3.0 \pm 0.2 \mathrm{mg}$ and $2.7 \pm 0.2 \mathrm{mg}$, respectively (Fig. 3A).

In addition to the lymph node weight the cell number and total amount of ATP, respectively increases due to cell proliferation. The standard curve illustrates the linear correlation of RLU and ATP, offering the following line equation: $\mathrm{y}=507.4 \times x+647.5$ (Fig. 3B). The ATP concentration was $272 \pm 213.4 \mu \mathrm{g} / \mathrm{mL}$ for the positive control and $57.45 \pm 11.64 \mu \mathrm{g} / \mathrm{mL}$ for the liquid negative control. As above, either CAP treatment $(31.23 \pm 11.37 \mu \mathrm{g} / \mathrm{mL})$ or argon treatment only $(10.66 \pm 2.99 \mu \mathrm{g} / \mathrm{mL})$ resulted in less proliferative findings than the liquid negative control (Fig. 3C).

Finally, the SI was highly increased in the positive control group $(\mathrm{SI}=4.67)$ and 


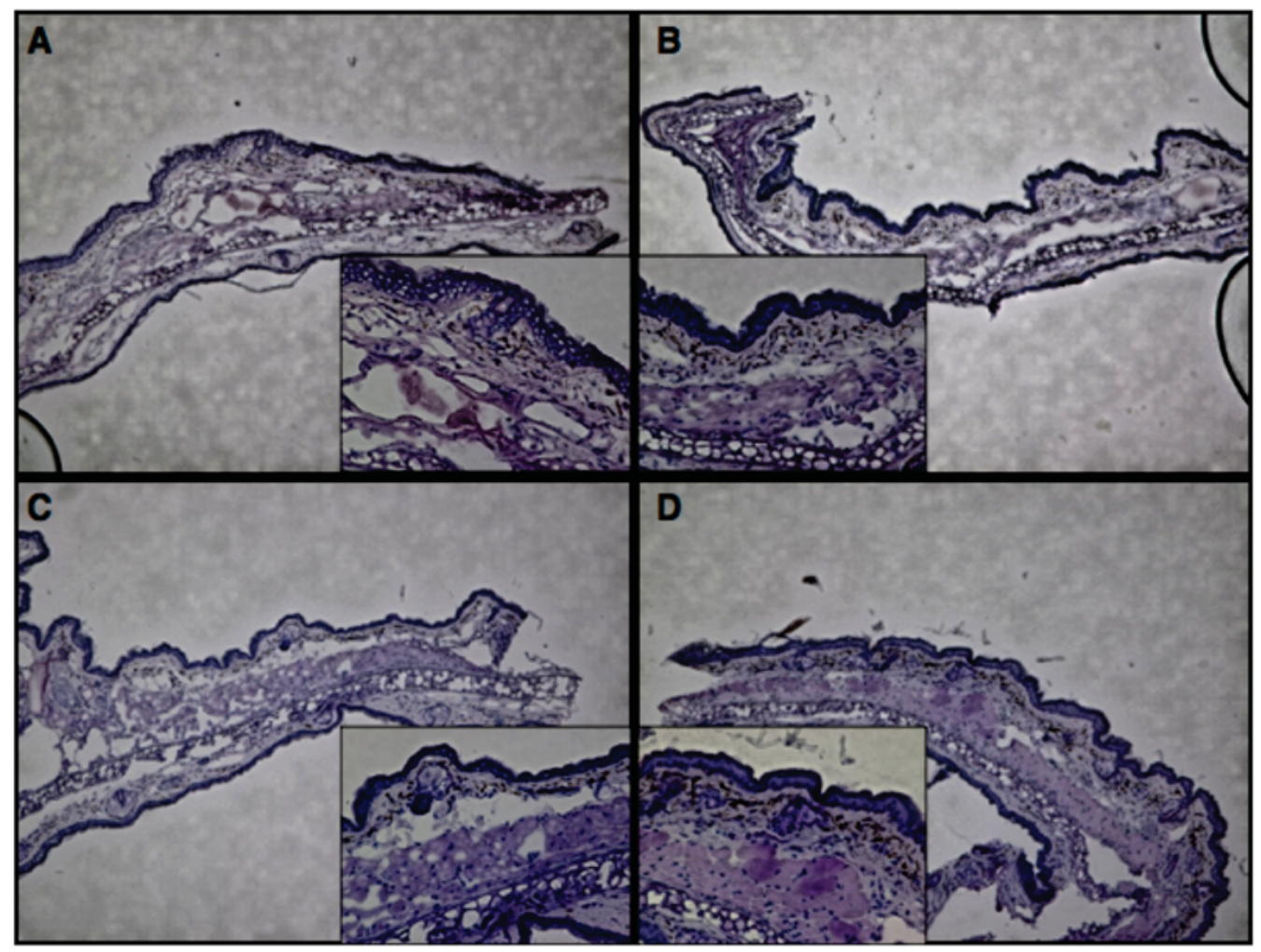

FIG. 2: H\&E-stained skin histology of mouse ears. (A) Positive control substance. (B) Negative control substance. (C) CAP treatment. (D) Argon gas. Both the total number of cells and cell size are increased. In addition, the stratum corneum appears thinner and partly abolished (A). No abnormality in skin structure was found (B-D). Magnification is $\times 10$ in the large images and $\times 40$ in the insets. The apical site in the microscopic pictures corresponds to the dorsal, substanceexposed ear surface. Fissuring is artificial due to preparation. CAP, cold atmospheric plasma; H\&E, hematoxylin and eosin.

moderately decreased for mice treated with either CAP or Argon gas only ( $\mathrm{SI}=0.76$ and 0.45 , respectively). When argon was used as the negative control, the SI for CAP-treated mice was still below the threshold $(\mathrm{SI}=1.66)$.

\section{DISCUSSION}

Plasma medicine is a new and very promising field of medical research with a comprehensive spectrum of possible future applications. Although there are currently no clinical reports of severe side effects occurring after CAP treatment, there might be additional immunologic effects that have not yet been evaluated. According to Paracelsus, every substance is toxic but its effect is dose dependent. Substantiating this ancient medical 
A

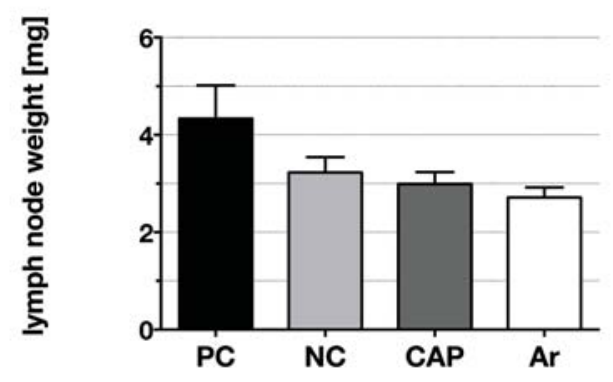

C

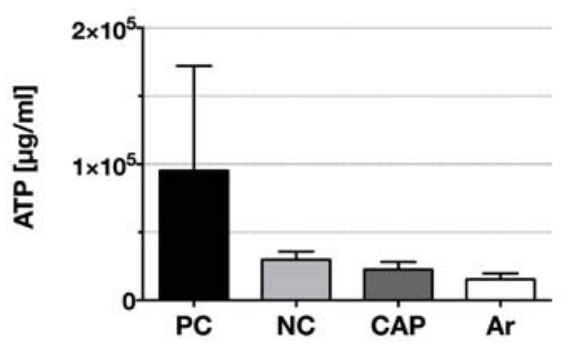

B

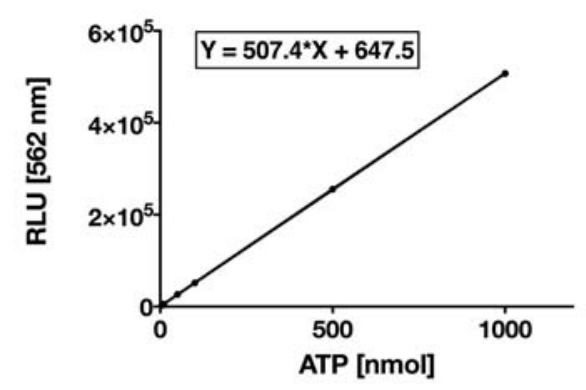

D

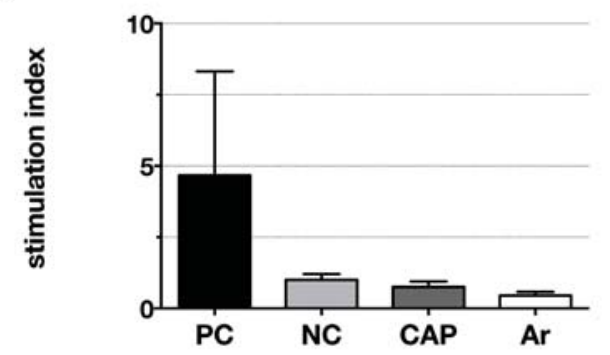

FIG. 3: Lymph node weight and ATP concentration remained unaffected by CAP treatment but not the positive control. (A) Lymph nodes from the positive control group show increased weight by trend, compared to all other groups. (B) The ATP amount was calculated via the standard curve equation: $\mathrm{y}=507.4 \times x+647.5$. (C) The ATP concentration in lymph nodes of the positive control group was highly elevated, whereas CAP treatment and argon only decreased the ATP concentration by trend, compared to the negative control. (D) Although the positive control group's SI was positive, CAP treatment and argon only led to a reduced SI. Ar, argon gas; ATP, adenosine triphosphate; CAP, cold atmospheric plasma; NC, negative control substance; PC, positive control substance.

rule, in vitro studies showed time-dependent effects from proliferation to apoptosis or even necrosis of nonmalignant cells. ${ }^{27,28}$ Potentially harmful agents (especially reactive oxygen species, UV radiation, ions, and electrons) were present in CAP and could possibly mediate skin sensitization.

Penetration of the skin barrier is a basic requirement for skin sensitization by exogenous irritants. For the kINPen MED, it has been shown that $3 \mathrm{~s}$ of treatment administered to intact human skin induced protein alterations in a penetration depth of the tissue of $25 \mu \mathrm{m},{ }^{29}$ suggesting the possibility of inducing sensitization. The high number of different plasma sources complicates structured exploration of the components and the biological impact of CAP in general. Hence, it would be beneficial if plasma tools 
could be compared on the basis of their output characteristics. In this setting, we treated each ear for $25 \mathrm{~s}$, which is equivalent to an effective UV dose of about $87.5 \mu \mathrm{J} / \mathrm{cm} 2$. This UV dose is below the minimal erythemal dose (MED) for an average European person. MED is a term used to describe the erythemal potential of UV radiation, and 1 MED is defined as the effective UV dose that causes a perceptible reddening of previously unexposed human skin, which varies between 200 and $500 \mathrm{~J} / \mathrm{m} 2$ among the European population. ${ }^{30}$ From this point of view, the application of CAP seems to be completely nonhazardous. In addition, CAP generated by the kINPen MED causes peak ozone concentrations of $238 \mathrm{ppb}$ in the vicinity of the nozzle $(\mathrm{x}=25 \mathrm{~mm})$ and encompasses a radius of approximately $5 \mathrm{~mm} .{ }^{31,32}$ It is well known that the lungs are highly susceptible to oxidative stress caused by ozone pollution ${ }^{33}$; by contrast, the human skin seems to be naturally resistant to ozone. Nevertheless, Valacchi et al. ${ }^{34}$ showed that the skin of mice developed oxidative stress after exposure to $8 \mathrm{ppm}$ of ozone for $2 \mathrm{~h}$ in a chamber.

As shown previously by Daeschlein et al. ${ }^{35}$ superficially performed CAP treatment with an older version of kINPen MED did not irritate the skin. In this study, the therapy procedure led to increased lymph node weight, ATP concentration, and SI in the positive control group but not in CAP- or argon-treated animals, indicating the suitability of argon-based CAP. Even in a comparison between CAP treatment and argon, the CAP SI value was below the threshold and is accordingly defined as a not-sensitizing substance. These results are in line with observations of several clinical studies to assess skin toleration of CAP. ${ }^{20,21,36}$

Our study has some limitations. According to Paracelsus, who pronounced that the dose makes the poison, only different treatment durations could picture a toxic doseeffect correlation. However, the CAP application used in this study reflects the effective setting of CAP assembled by the kINPen MED. ${ }^{37}$ Next, according to the LLNA:DA protocol, limitations of gaseous CAP application were compared to the liquid positive and negative controls. Although $\alpha$-hexyl cinnamic aldehyde is recommended for use as a positive control because results are typically positive and notably reproducible, ${ }^{38}$ differences in the sensitization potency of gaseous and liquid states of aggregation cannot be excluded (especially because different test results were observed, subject to varied vehicle substances).$^{39}$ Finally, CAP treatment was carried out on an intact skin barrier. This study design allows no statement of the reaction in altered or disturbed skin barrier function, such as chronic wounds or dermatologic diseases, as they show per se a proinflammatory microenvironment. ${ }^{40}$ However, local recurrent CAP application, generated by a different argon plasma jet, has been shown to decrease cutaneous immune cell invasion by inhibition of chemokine expression in a murine model of atopic dermatitis, leading to reduced inflammation. ${ }^{41}$

\section{CONCLUSION}

Altogether, this study is the first to investigate the sensitization potential of CAP in vivo by LLNA:DA. We found repeated CAP application of a moderate duration to intact skin to be safe in this respect, as neither histological skin damage nor local lymphocyte 
proliferation was detectable. Based on these results and clinical experience, therapeutic CAP treatment (at least, that generated by kINPen MED) seems to be unobjectionable from an immunologic point of view. As it is a long way from the bench to the bedside, further research is necessary to prove whether the high concentrations of ozone near the plume of the kINPen MED have any effects on the skin and oxidative stress levels in the tissue. Our study provides promising results, as we could not detect any abnormal proliferation activity in the local skin or lymph nodes, substantiating current assessment of risks in CAP application.

\section{ACKNOWEDGMENIS}

Funding was received from the German Federal Ministry of Education and Research (BMBF Grant Nos. 13N9779 and 13N11181). K.R.L. was supported by a GerhardDomagk research grant from the Medical Faculty of the Ernst-Moritz-Arndt University Greifswald. We also thank Antje Janetzko and Julia Bordasch for technical assistance.

\section{REFERENCES}

1. Kramer A, Lademann J, Bender C, Sckell A, Hartmann B, Münch S, Hinz P, Ekkernkamp A, Matthes R, Koban I, Partecke I. Suitability of tissue tolerable plasmas (TTP) for the management of chronic wounds. Clin Plasma Med. 2013;1(1):11-8.

2. Hammann A, Huebner NO, Bender C, Ekkernkamp A, Hartmann B, Hinz P, Kindel E, Koban I, Koch S, Kohlmann T, Lademann J. Antiseptic efficacy and tolerance of tissue-tolerable plasma compared with two wound antiseptics on artificially bacterially contaminated eyes from commercially slaughtered pigs. Skin Pharmacol Physiol. 2010;23(6):328-32.

3. Matthes R, Lührman A, Holtfreter S, Kolata J, Radke D, Hübner NO, Assadian O, Kramer A. Antibacterial activity of cold atmospheric pressure argon plasma against 78 genetically different (mecA, luk-P, agr or capsular polysaccharide type) Staphylococcus aureus strains. Skin Pharmacol Physiol. 2016;29(2):83-91.

4. Bender C, Matthes R, Kindel E, Kramer A, Lademann J, Weltmann KD, Eisenbeiß W, Hübner NO. The irritation potential of nonthermal atmospheric pressure plasma in the HET-CAM. Plasma Processes Polym. 2010;7(3-4):318-26.

5. Bender C, Partecke LI, Kindel E, Doring F, Lademann J, Heidecke CD, Kramer A, Hübner NO. The modified HET-CAM as a model for the assessment of the inflammatory response to tissue tolerable plasma. Toxicol In Vitro. 2011;25(2):530-7.

6. Ahn HJ, Kim KI, Kim G, Moon E, Yang SS, Lee JS. Atmospheric-pressure plasma jet induces apoptosis involving mitochondria via generation of free radicals. PLoS One. 2011;6(11):e28154.

7. Fridman G, Shereshevsky A, Jost MM, Brooks AD, Fridman A, Gutsol A, Vasilets V, Friedman G. Floating electrode dielectric barrier discharge plasma in air promoting apoptotic behavior in melanoma skin cancer cell lines. Plasma Chem Plasma Process. 2007;27(2):163-76.

8. Partecke L, Evert K, Haugk J, Doering F, Normann L, Diedrich S, Weiss FU, Evert M, Huebner NO, Guenther C, Heidecke CD. Tissue tolerable plasma (TTP) induces apoptosis in pancreatic cancer cells in vitro and in vivo. BMC Cancer. 2012;12(1):473.

9. Kramer A, Bekeschus S, Matthes R, Bender C, Stope MB, Napp M, Lademann O, Lademann J, Weltmann KD, Schauer F. Cold physical plasmas in the field of hygiene-relevance, significance, and future applications. Plasma Processes Polym. 2015;12(12):1410-22.

10. Zhou XC, Li YL, Liu DX, Cao YG, Lu XP. Bactericidal effect of plasma jet with helium flowing

Volume 7, Issue 4, 2017 
through 3\% hydrogen peroxide against Enterococcus faecalis. Exp Ther Med. 2016;12(5):3073-7.

11. von Woedtke T, Kramer A, Weltmann KD. Plasma sterilization: what are the conditions to meet this claim? Plasma Processes Polym. 2008;5(6):534-9.

12. Cha S, Park YS. Plasma in dentistry. Clin Plasma Med. 2014;2(1):4-10.

13. Heinlin J, Morfill G, Landthaler M, Stolz W, Isbary G, Zimmermann JL, Shimizu T, Karrer S. Plasma medicine: possible applications in dermatology. J Deutschen Dermatologischen Gesellschaft. 2010;8(12):968-76.

14. von Woedtke T, Metelmann HR, Weltmann KD. Clinical plasma medicine: state and perspectives of in vivo application of cold atmospheric plasma. Contrib Plasma Phys. 2014;54(2):104-17.

15. Dean JH, Twerdok LE, Tice RR, Sailstad DM, Hattan DG, Stokes WS. ICCVAM evaluation of the murine local lymph node assay. Regul Toxicol Pharmacol. 2001;34(3):258-73.

16. Gerberick GF, Ryan CA, Dearman RJ, Kimber I. Local lymph node assay (LLNA) for detection of sensitization capacity of chemicals. Methods. 2007;41(1):54-60.

17. Green CM, Holden CR, Gawkrodger DJ. Contact allergy to topical medicaments becomes more common with advancing age: an age-stratified study. Contact Dermatitis. 2007;56(4):229-31.

18. Shih YH, Sun CC, Tseng YH, Chu CY. Contact dermatitis to topical medicaments: a retrospective study from a medical center in Taiwan. Dermatol Sinica. 2015;33(4):181-6.

19. Bekeschus S, Schmidt A, Weltmann K-D, von Woedtke T. The plasma jet kINPen - A powerful tool for wound healing. Clin Plasma Med. 2016;4(1):19-28.

20. Lademann J, Ulrich C, Patzelt A, Richter H, Kluschke F, Klebes M, Lademann O, Kramer A, Weltmann KD. Risk assessment of the application of tissue-tolerable plasma on human skin. Clin Plasma Med. 2013;1(1):5-10.

21. Isbary G, Zimmermann JL, Shimizu T, Li YF, Morfill GE, Thomas HM, Steffes B, Heinlin J, Karrer S, Stolz W. Non-thermal plasma-more than five years of clinical experience. Clin Plasma Med. 2013;1(1):19-23.

22. Martin SF, Esser PR, Weber FC, Jakob T, Freudenberg MA, Schmidt M, Goebeler M. Mechanisms of chemical-induced innate immunity in allergic contact dermatitis. Allergy. 2011;66(9):1152-63.

23. Kaushik N, Uddin N, Sim GB, Hong YJ, Baik KY, Kim CH, Lee SJ, Kaushik NK, Choi EH. Responses of solid tumor cells in DMEM to reactive oxygen species generated by non-thermal plasma and chemically induced ROS systems. Sci Rep. 2015;5:8587.

24. Wende K, Strassenburg S, Haertel B, Harms M, Holtz S, Barton A, Masur K, von Woedtke T, Lindequist U. Atmospheric pressure plasma jet treatment evokes transient oxidative stress in HaCaT keratinocytes and influences cell physiology. Cell Biol Int. 2014;38(4):412-25.

25. Interagency Coordinating Committee on the Validation of Alternative Methods (ICCVAM). ICCVAM test method evaluation report on the murine local lymph node assay: DA. A nonradioactive alternative test method to assess the allergic contact dermatitis potential of chemicals and products. Research Triangle Park (NC): National Toxicology Program; 2010.

26. Idehara K, Yamagishi G, Yamashita K, Ito M. Characterization and evaluation of a modified local lymph node assay using ATP content as a non-radio isotopic endpoint. J Pharmacol Toxicol Methods. 2008;58(1):1-10.

27. Hirst AM, Simms MS, Mann VM, Maitland NJ, O’Connell D, Frame FM. Low-temperature plasma treatment induces DNA damage leading to necrotic cell death in primary prostate epithelial cells. $\mathrm{Br} \mathrm{J}$ Cancer. 2015;112(9):1536-45.

28. Bundscherer L, Nagel S, Hasse S, Tresp H, Wende K, Walther R, Reuter S, Weltmann KD, Masur K, Lindequist U. Non-thermal plasma treatment induces MAPK signaling in human monocytes. Open Chem. 2014;13(1):606-13.

29. Fluhr JW, Sassning S, Lademann O, Darvin ME, Schanzer S, Kramer A, Richter H, Sterry W, Lademann J. In vivo skin treatment with tissue-tolerable plasma influences skin physiology and antioxidant profile in human stratum corneum. Exp Dermatol. 2012;21(2):130-4.

30. Vanicek K, Frei T, Litynska Z, Schmalwieser A. COST-713 Action UVB forecasting: UV index for the 
public. Brussels (Belgium): European Communities; 2000.

31. Kelly S, Gogna GS, Monaghan R, Daniels S. Ozone mapping the kINPen-MED plasma jet. Presented at the 32nd International Conference on Phenomena in Ionized Gases; 2015 Jul 26-31; Iași, Romania.

32. Ansgar SB, Jörn W, André B, Stephan R, Klaus-Dieter W. On the plasma chemistry of a cold atmospheric argon plasma jet with shielding gas device. Plasma Sources Sci Technol. 2016;25(1):015005.

33. Jerrett M, Burnett RT, Pope CA 3rd, Ito K, Thurston G, Krewski D, Shi Y, Calle E, Thun M. Long-term ozone exposure and mortality. New England J Med. 2009;360(11):1085-95.

34. Valacchi G, van der Vliet A, Schock BC, Okamoto T, Obermuller-Jevic U, Cross CE, Packer L. Ozone exposure activates oxidative stress responses in murine skin. Toxicology. 2002;179(1-2):163-70.

35. Daeschlein G, Scholz S, Ahmed R, von Woedtke T, Haase H, Niggemeier M, Kindel E, Brandenburg $\mathrm{R}$, Weltmann KD, Juenger M. Skin decontamination by low-temperature atmospheric pressure plasma jet and dielectric barrier discharge plasma. J Hosp Infect. 2012;81(3):177-83.

36. Heinlin J, Isbary G, Stolz W, Zeman F, Landthaler M, Morfill G, Shimizu T, Zimmermann JL, Karrer S. A randomized two-sided placebo-controlled study on the efficacy and safety of atmospheric nonthermal argon plasma for pruritus. J Eur Acad Dermatol Venereol. 2013;27(3):324-31.

37. Weltmann KD, von Woedtke T. Campus PlasmaMed - from basic research to clinical proof. IEEE Trans Plasma Sci. 2011;39(4):1015-25.

38. Dearman RJ, Wright ZM, Basketter DA, Ryan CA, Gerberick GF, Kimber I. The suitability of hexyl cinnamic aldehyde as a calibrant for the murine local lymph node assay. Contact Dermatitis. 2001;44(6):357-61.

39. Jowsey IR, Clapp CJ, Safford B, Gibbons BT, Basketter DA. The impact of vehicle on the relative potency of skin-sensitizing chemicals in the local lymph node assay. Cutan Ocul Toxicol. 2008;27(2):6775.

40. Finley PJ, DeClue CE, Sell SA, DeBartolo JM, Shornick LP. Diabetic wounds exhibit decreased Ym1 and arginase expression with increased expression of IL-17 and IL-20. Adv Wound Care (New Rochelle). 2016;5(11):486-94.

41. Choi JH, Song YS, Lee HJ, Hong JW, Kim GC. Inhibition of inflammatory reactions in 2,4-dinitrochlorobenzene induced Nc/Nga atopic dermatitis mice by non-thermal plasma. Sci Rep. 2016;6:27376. 